\title{
Galantamine Hydrobromide
}

National Cancer Institute

\section{Source}

National Cancer Institute. Galantamine Hydrobromide. NCI Thesaurus. Code C47546.

The hydrobromide salt form of galantamine, a tertiary alkaloid obtained synthetically or naturally from the bulbs and flowers of Narcissus and several other genera of the Amaryllidaceae family with anticholinesterase and neurocog nitive-enhancing activities. Galantamine competitively and reversibly inhibits acetylcholinesterase, thereby increasing the concentration and enhancing the action of acetylcholine (Ach). In addition, galantamine is a ligand for nicotinic acetylcholine receptors, which may increase the presynaptic release of Ach and activate postsynaptic receptors. This agent may improve neurocog nitive function in mild and moderate Alzheimer' $s$ disease and may reduce abstinence-induced cog nitive symptoms that promote smoking relapse. 